\title{
A COMPARISON OF HUMAN PHYSICAL MODELS BASED ON THE DISTRIBUTION OF POWER IN A DYNAMIC STRUCTURE IN THE CASE OF HAND-ARM VIBRATIONS
}

\author{
Marian Witalis Dobry, Tomasz Hermann \\ Poznan University of Technology, Institute of Applied Mechanics, Poznań, Poland \\ e-mail:marian.dobry@put.poznan.pl; tomasz.hermann@put.poznan.pl
}

\begin{abstract}
The main aim of this study is to present an energy comparison of two human physical models taking into account hand-arm vibrations, which are based on the power distribution in their dynamic structure. The method used in the study takes advantage of a close relationship between the dynamics of the systems and energy-related phenomena that occur within them. The energy comparison of the two human physical models required construction of energy models of a Human-Tool system and finding their solutions. For this purpose, programs have been developed using the MATLAB/simulink software to simulate power distribution in the systems. The simulation revealed a discrepancy between the two models in terms of three types of powers and globally in the system as a whole.
\end{abstract}

Keywords: hand-arm vibrations, biomechanical system, power distribution

\section{Introduction}

Research on the impact of vibrations on the human body is carried out in many research centers around the world. Many studies in this area have contributed to the expansion of knowledge about the impact of vibrations on the human body, in particular studies by Griffin (1990), Reynolds and Soedel (1972), Meltzer (1981) and many others (Adewusi et al., 2012). One of the basic problems, which has frequently been addressed, is the construction of a suitable human biomechanical model.

At present, several models are used for analysis which differ, first of all, in terms of the number of components and the way in which they are connected. In addition to the already existing systems, new models are being created to replace the previous ones and to better reflect the human response to mechanical vibrations. Choosing the right model is, therefore, becoming increasingly difficult. Consequently, this study attempted to compare two latest human physical models that have been used in recent studies. A measure of model adequacy should reflect to what extent a given model correctly represents energy phenomena which occur in the dynamic structure and in the entire system during its operation.

The main aim of this study is to assess the adequacy of four conditional variants of the human physical model for hand-arm vibrations presented in Dong et al. (2007). The new physical model has been verified by comparing its energy inputs with the values obtained by means of a model with three points of reduction, which is specified in ISO 10068 (ISO 10068:1998). The two human physical models have been tested with respect to the power distribution in the dynamic structure and the test results served as the basis for a comparative assessment of the investigated biomechanical systems.

Assessment of the human physical models for hand-arm vibrations in terms of energy inputs involved solving a set of differential equations of motion constituting the mathematical model, which are derived from Lagrange's equations of the second kind expressed as 


$$
\frac{d}{d t}\left(\frac{\partial E}{\partial \dot{q}_{j}}\right)-\frac{\partial E}{\partial q_{j}}=Q_{j}+Q_{j P}+Q_{j R} \quad j=1,2, \ldots, s
$$

where: $E$ is the kinetic energy of the system, $q_{j}-$ generalized coordinates, $\dot{q}_{j}-$ generalized velocity, $Q_{j}$ - active external forces, $Q_{j P}$ - potential forces, $Q_{j R}$-non-potential forces dependent on the power of dissipation, $s$ - number of degrees of freedom.

In the models in question, it is necessary to assume generalized coordinates to clearly describe the displacement. The following generalized coordinates have been adopted in the model with three points of reduction specified in the ISO 10068 standard (Fig. 2a):

$$
\begin{aligned}
& \left.j=1 \Rightarrow q_{1}=z_{1}(t) \quad-\quad \text { displacement of the point of reduction Arm-Shoulder (mass } m_{1}\right), \\
& j=2 \Rightarrow q_{2}=z_{2}(t) \quad-\quad \begin{array}{l}
\text { displacement of the point of reduction Forearm-Elbow } \\
\left(\text { mass } m_{2}\right),
\end{array} \\
& \begin{array}{l}
\text { displacement of the point of reduction Tool-Hand (mass } m_{3} \\
\text { and } \left.m_{N}\right) .
\end{array}
\end{aligned}
$$

In the combined physical model of the human and the tool (Fig. 2b), the following generalized coordinates have been assumed:

$$
\begin{aligned}
& j=1 \Rightarrow q_{1}=z_{1}(t) \quad-\quad \begin{array}{l}
\text { displacement of the Upper Arm-Shoulder point of reduction } \\
\left(\text { mass } m_{1}\right),
\end{array} \\
& j=2 \Rightarrow q_{2}=z_{2}(t) \quad-\quad \begin{array}{l}
\text { displacement of the Palm-Wrist-Forearm point of reduction } \\
\left(\text { mass } m_{2}\right),
\end{array} \\
& \begin{array}{ll}
\left.j=3 \Rightarrow q_{3}=z_{3}(t) \quad-\quad \text { displacement of the Fingers point of reduction (mass } m_{3}\right), \\
j=4 \Rightarrow q_{4}=z_{4}(t) \quad-\quad \text { displacement of the sum of masses } m_{3}, m_{4} \text { and } m_{N} .
\end{array}
\end{aligned}
$$

The differential equations of motion have been solved using a simulation program developed in the MATLAB/simulink environment. The use of an Elementary Processor of Energy Flow and Power Distribution (EPEFPD) made it possible to determine the power distribution in the biomechanical system, in particular changes in momentary values of the power of inertia, loss and elasticity. Individual powers of structural forces have been added to calculate the total power and determine the order of energy inputs introduced into the biological structure under the human physical models analyzed in the study.

\section{Theoretical basis - The First Principle of Power Distribution in a Mechanical System}

The First Principle of Power Distribution in a Mechanical System can be expressed in the following way (Dobry, 1998, 2001, 2004, 2012):

"The net input power introduced into the mechanical system (after subtracting the power of dissipation) is equal to the reflected power (accumulated or stored) in the system and the output power generated by the system."

This rule can be expressed in the following mathematical form (Dobry, 1998, 2001, 2004, 2012)

$$
P_{\text {in }}(t)-P_{\text {los }}(t)=P_{\text {ref }}(t)+P_{\text {out }}(t)
$$

where:

- power of the resultant force - the drive input power introduced into the mechanical system (power input)

$$
P_{\text {in }}(t)=\mathbf{W}_{\text {in }}(t) \cdot \mathbf{v}_{\text {in }}(t)
$$


- power of dissipation equal to the sum of internal losses in the system and the power of inertia in the system

$$
P_{\text {los }}(t)=P_{\text {int los }}(t)+\mathbf{R}(t) \cdot \mathbf{v}_{R}(t)
$$

- reflected power in the mechanical system equal to the sum of the power of inertia and the power of elasticity

$$
P_{r e f}(t)=\mathbf{B}(t) \cdot \mathbf{v}_{B}(t)+\mathbf{S}(t) \cdot \mathbf{v}_{S}(t)
$$

— output power equal to the output power of a mechanical system

$$
P_{\text {out }}(t)=\mathbf{O}(t) \cdot \mathbf{v}_{\text {out }}(t)
$$

The First Principle of Power Distribution in a Mechanical System (FPPDMS) can be represented graphically, as shown in Fig. 1.

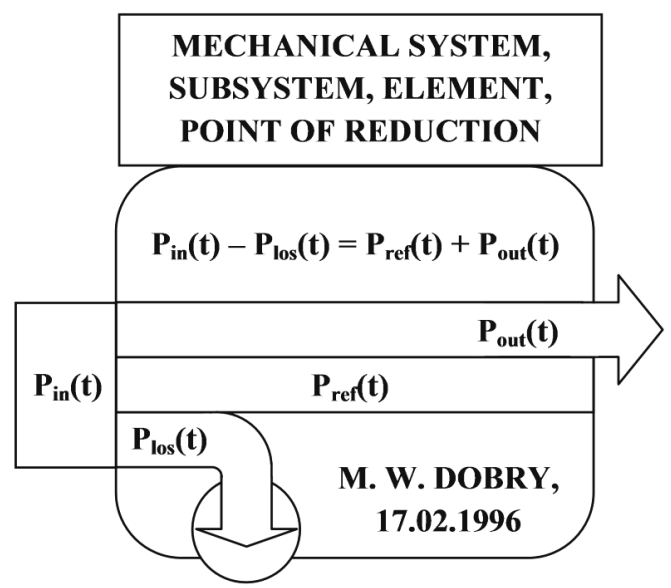

Fig. 1. A graphical representation of the First Principle of Power Distribution in Mechanical System (FPPDMS) and the universal model of power distribution in mechanical systems, their subsystems, elements and in points of reduction (Dobry, 1998, 2001, 2004, 2012)

\section{Methods of solving the problem}

Figure $2 \mathrm{~b}$ shows the physical model which combines the new model of the human body proposed by Dong et al. (2007) with the model of the tool. The results obtained by means of the new model to analyze vibrations acting on the human body through the upper limbs (hand-arm vibrations) are compared with those generated by the model with three points of reduction (nine-degrees of freedom), specified in ISO 10068 (ISO 10068:1998). That model is then combined with the tool, as shown in Fig. 2a.

The two combined models are discrete in the sense that their corresponding points of reduction are connected by means of elastic and damping systems which model the elastic and damping properties of the human body.

Mathematical models of the dynamic structures are derived using equation (1.1), assuming, for the sake of simplicity, only one main direction of vibration - along the $z$ axis. The mathematical model of the Human-Tool system constructed on the basis of the human model with three points of reduction specified in the ISO 10068 standard (ISO 10068:1998) (Fig. 2a), has 
(a)

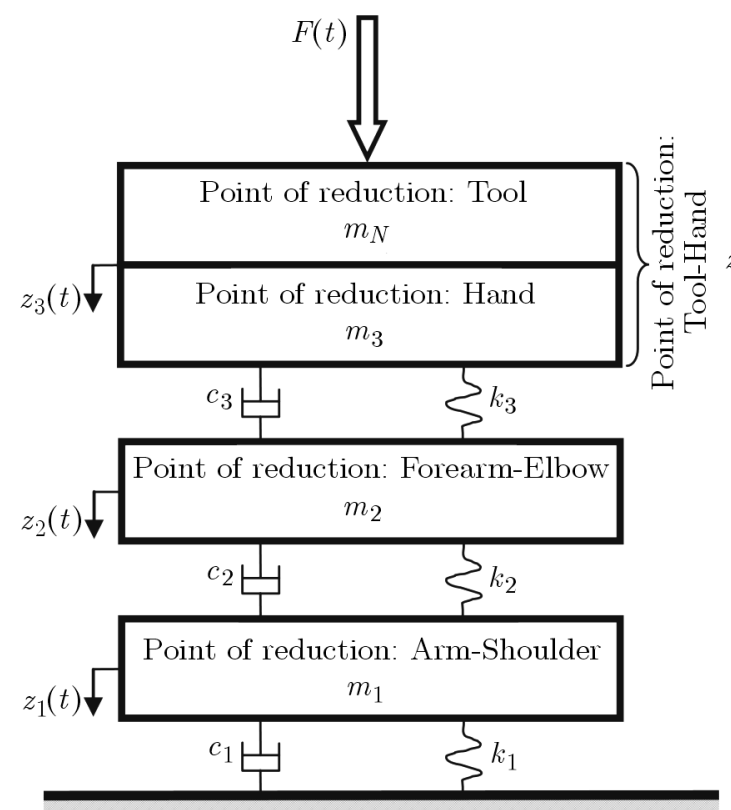

(b)

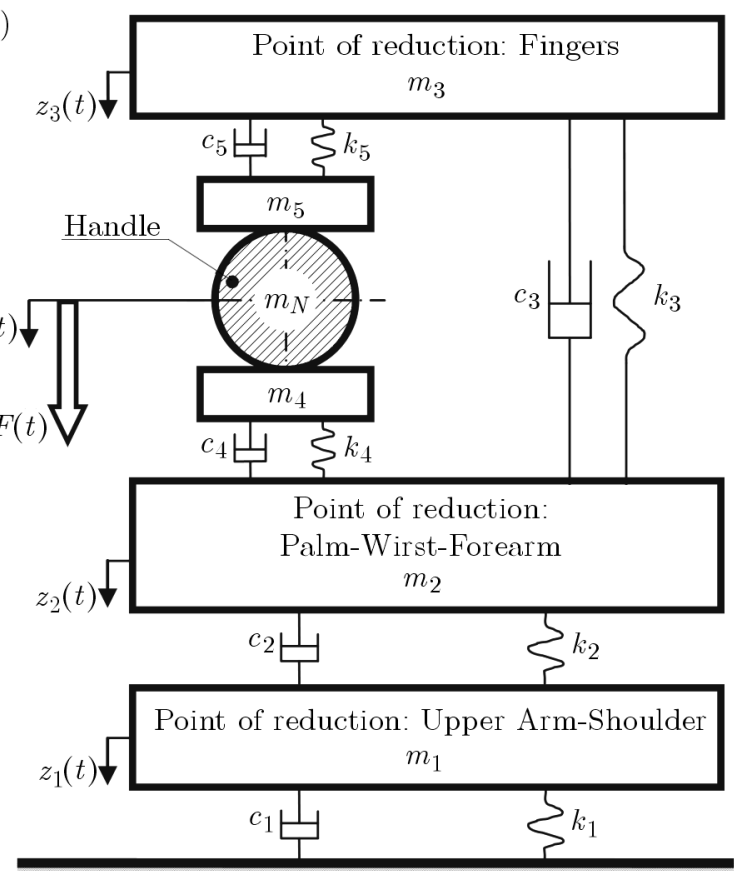

Fig. 2. Physical models of the Human-Tool system: (a) the model specified in ISO 10068 (ISO 10068:1998) combined with the model of the tool, (b) the new human physical model proposed by Dong et al. (2007) combined with the model of the tool

the form

$$
\begin{array}{ll}
j=1 & m_{1} \ddot{z}_{1}+\left(c_{1}+c_{2}\right) \dot{z}_{1}+\left(k_{1}+k_{2}\right) z_{1}-c_{2} \dot{z}_{2}-k_{2} z_{2}=0 \\
j=2 & m_{2} \ddot{z}_{2}+\left(c_{2}+c_{3}\right) \dot{z}_{2}+\left(k_{2}+k_{3}\right) z_{2}-c_{2} \dot{z}_{1}-k_{2} z_{1}-c_{3} \dot{z}_{3}-k_{3} z_{3}=0 \\
j=3 & \left(m_{3}+m_{N}\right) \ddot{z}_{3}+c_{3} \dot{z}_{3}+k_{3} z_{3}-c_{3} \dot{z}_{2}-k_{3} z_{2}=F(t)
\end{array}
$$

The mathematical model of the second combined human-tool model (Fig. 2b) can be written as

$$
\begin{array}{ll}
j=1 & m_{1} \ddot{z}_{1}+\left(c_{1}+c_{2}\right) \dot{z}_{1}+\left(k_{1}+k_{2}\right) z_{1}-c_{2} \dot{z}_{2}-k_{2} z_{2}=0 \\
j=2 & m_{2} \ddot{z}_{2}+\left(c_{2}+c_{3}+c_{4}\right) \dot{z}_{2}+\left(k_{2}+k_{3}+k_{4}\right) z_{2}-c_{2} \dot{z}_{1}-k_{2} z_{1}-c_{3} \dot{z}_{3} \\
& -k_{3} z_{3}-c_{4} \dot{z}_{4}-k_{4} z_{4}=0 \\
& \\
j=3 & m_{3} \ddot{z}_{3}+\left(c_{3}+c_{5}\right) \dot{z}_{3}+\left(k_{3}+k_{5}\right) z_{3}-c_{3} \dot{z}_{2}-k_{3} z_{2}-c_{5} \dot{z}_{4}-k_{5} z_{4}=0 \\
j=4 & \left(m_{4}+m_{5}+m_{N}\right) \ddot{z}_{4}+\left(c_{4}+c_{5}\right) \dot{z}_{4}+\left(k_{4}+k_{5}\right) z_{4}-c_{4} \dot{z}_{2}-k_{4} z_{2} \\
& -c_{5} \dot{z}_{3}-k_{5} z_{3}=F(t)
\end{array}
$$

Differential equations of motion (3.1) and (3.2) are the basis of constructing energy models for the systems in question. After applying the First Principle of Power Distribution in a Mechanical System (2.1), it is possible to switch from the conventional dynamic analysis of amplitudes to the energy analysis of power distribution.

Equations (2.2)-(2.5) are used to construct an energy model of the Human-Tool system based on the model specified in the ISO 10068 standard (3.1). In this case, the energy model has the following form

$$
\begin{array}{ll}
j=1 & m_{1} \ddot{z}_{1} \dot{z}_{1}+\left(c_{1}+c_{2}\right) \dot{z}_{1}^{2}+\left(k_{1}+k_{2}\right) z_{1} \dot{z}_{1}-c_{2} \dot{z}_{2} \dot{z}_{1}-k_{2} z_{2} \dot{z}_{1}=0 \\
j=2 & m_{2} \ddot{z}_{2} \dot{z}_{2}+\left(c_{2}+c_{3}\right) \dot{z}_{2}^{2}+\left(k_{2}+k_{3}\right) z_{2} \dot{z}_{2}-c_{2} \dot{z}_{1} \dot{z}_{2}-k_{2} z_{1} \dot{z}_{2}-c_{3} \dot{z}_{3} \dot{z}_{2} \\
& -k_{3} z_{3} \dot{z}_{2}=0 \\
& \left(m_{3}+m_{N}\right) \ddot{z}_{3} \dot{z}_{3}+c_{3} \dot{z}_{3}^{2}+k_{3} z_{3} \dot{z}_{3}-c_{3} \dot{z}_{2} \dot{z}_{3}-k_{3} z_{2} \dot{z}_{3}=F(t) \dot{z}_{3}
\end{array}
$$


Thus, the corresponding energy model of the Human-Tool system based on the new human physical model (3.2) can be written thus

$$
\begin{array}{ll}
j=1 & m_{1} \ddot{z}_{1} \dot{z}_{1}+\left(c_{1}+c_{2}\right) \dot{z}_{1}^{2}+\left(k_{1}+k_{2}\right) z_{1} \dot{z}_{1}-c_{2} \dot{z}_{2} \dot{z}_{1}-k_{2} z_{2} \dot{z}_{1}=0 \\
j=2 & m_{2} \ddot{z}_{2} \dot{z}_{2}+\left(c_{2}+c_{3}+c_{4}\right) \dot{z}_{2}^{2}+\left(k_{2}+k_{3}+k_{4}\right) z_{2} \dot{z}_{2}-c_{2} \dot{z}_{1} \dot{z}_{2}-k_{2} z_{1} \dot{z}_{2} \\
& -c_{3} \dot{z}_{3} \dot{z}_{2}-k_{3} z_{3} \dot{z}_{2}-c_{4} \dot{z}_{4} \dot{z}_{2}-k_{4} z_{4} \dot{z}_{2}=0 \\
j=3 & m_{3} \ddot{z}_{3} \dot{z}_{3}+\left(c_{3}+c_{5}\right) \dot{z}_{3}^{2}+\left(k_{3}+k_{5}\right) z_{3} \dot{z}_{3}-c_{3} \dot{z}_{2} \dot{z}_{3}-k_{3} z_{2} \dot{z}_{3}-c_{5} \dot{z}_{4} \dot{z}_{3} \\
& -k_{5} z_{4} \dot{z}_{3}=0 \\
j=4 & \left(m_{4}+m_{5}+m_{N}\right) \ddot{z}_{4} \dot{z}_{4}+\left(c_{4}+c_{5}\right) \dot{z}_{4}^{2}+\left(k_{4}+k_{5}\right) z_{4} \dot{z}_{4}-c_{4} \dot{z}_{2} \dot{z}_{4} \\
& -k_{4} z_{2} \dot{z}_{4}-c_{5} \dot{z}_{3} \dot{z}_{4}-k_{5} z_{3} \dot{z}_{4}=F(t) \dot{z}_{4}
\end{array}
$$

The energy models of the two Human-Tool systems have been implemented in the MATLAB/simulink environment to determine changes in momentary values of the power of inertia, loss and elasticity. The simulation results have been used to assess the models in terms of energy flows in the system. They also demonstrated differences between the new human model (Dong et al., 2007) and the currently used model specified in the ISO 10068:1998 standard.

\section{Energy comparison of biomechanical Human-Tool systems with studied human models}

Energy analysis has been carried out for a sinusoidal driving force $F(t)$ with an amplitude of $200 \mathrm{~N}$ at different frequencies $f$ in Hz. The analysis has been conducted for four frequency values: $16 \mathrm{~Hz}, 30 \mathrm{~Hz}, 60 \mathrm{~Hz}$ and $90 \mathrm{~Hz}$, assuming the mass of the tool $m_{N}$ to be $6 \mathrm{~kg}$. In each case, the simulation time $t$ has been set to 300 seconds to allow an acceptable average deviation of power values (less than 3\%) for each of the models. Simulations in the MATLAB/simulink software have been implemented using integration time steps ranging from a maximum of 0.001 to a minimum of 0.0001 second. The integration procedure ode113 (Adams) with a tolerance of 0.001 has been used. Values of dynamic parameters used in the simulations have been set according to specifications in the ISO 10068 (ISO 10068:1998) standard and in Dong et al. (2007). The simulation has been performed assuming different values of forces exerted by the human operator on the tool (Table 1).

Table 1. Variants of forces in the new human physical model by Dong et al. (2007)

\begin{tabular}{|l|c|c|c|c|}
\hline The force of & Variant I (V1) & Variant II (V2) & Variant III (V3) & Variant IV (V4) \\
\hline \hline grip $F_{g}[\mathrm{~N}]$ & 50 & 15 & 30 & 50 \\
\hline pushing $F_{p}[\mathrm{~N}]$ & - & 35 & 45 & 50 \\
\hline
\end{tabular}

In the case of the new human physical model, four sets of dynamic parameters are available (Table 2), which correspond to four different conditions of the human interaction with the handle of the tool. Each variant corresponds to a different value of the grip force of the hand $F_{g}$ and the pushing force exerted on the handle $F_{p}$ (Table 1 ).

Table 3 shows values of the dynamic parameters for the model specified in the ISO 10068 standard (ISO 10068:1998). The dynamic analysis of this model takes into account, as already mentioned, only the main direction of hand-arm vibrations, namely parameters for the $z$ direction.

Figure 3 shows the effect of frequency of the driving impulses $f$ on the percentage increase in the contribution of the three types of power in the new model compared to values obtained 
Table 2. Values of the dynamic parameters of the new human physical model for different conditions of the human interaction with the handle of the tool (Dong et al., 2007)

\begin{tabular}{|c|c|c|c|c|c|}
\hline Parameter & Unit & Variant I (V1) & Variant II (V2) & Variant III (V3) & Variant IV (V4) \\
\hline \hline$m_{1}$ & $\mathrm{~kg}$ & 5.854 & 6.099 & 6.505 & 5.863 \\
\hline$m_{2}$ & $\mathrm{~kg}$ & 1.324 & 0.850 & 0.977 & 1.248 \\
\hline$m_{3}$ & $\mathrm{~kg}$ & 0.083 & 0.084 & 0.080 & 0.083 \\
\hline$m_{4}$ & $\mathrm{~kg}$ & 0.025 & 0.029 & 0.031 & 0.029 \\
\hline$m_{5}$ & $\mathrm{~kg}$ & 0.013 & 0.011 & 0.012 & 0.013 \\
\hline$k_{1}$ & $\mathrm{~N} / \mathrm{m}$ & 13740 & 17270 & 18830 & 16900 \\
\hline$k_{2}$ & $\mathrm{~N} / \mathrm{m}$ & 2460 & 2420 & 1020 & 1700 \\
\hline$k_{3}$ & $\mathrm{~N} / \mathrm{m}$ & 6790 & 3450 & 4030 & 4040 \\
\hline$k_{4}$ & $\mathrm{~N} / \mathrm{m}$ & 26190 & 38680 & 48930 & 52490 \\
\hline$k_{5}$ & $\mathrm{~N} / \mathrm{m}$ & 157120 & 56150 & 96310 & 143920 \\
\hline$c_{1}$ & $\mathrm{~N} \cdot \mathrm{s} / \mathrm{m}$ & 107.07 & 152.87 & 163.76 & 169.7 \\
\hline$c_{2}$ & $\mathrm{~N} \cdot \mathrm{s} / \mathrm{m}$ & 97.80 & 159.20 & 158.94 & 140.53 \\
\hline$c_{3}$ & $\mathrm{~N} \cdot \mathrm{s} / \mathrm{m}$ & 39.03 & 25.26 & 28.97 & 35.47 \\
\hline$c_{4}$ & $\mathrm{~N} \cdot \mathrm{s} / \mathrm{m}$ & 81.79 & 86.53 & 101.31 & 114.83 \\
\hline$c_{5}$ & $\mathrm{~N} \cdot \mathrm{s} / \mathrm{m}$ & 127.98 & 74.73 & 99.87 & 124.59 \\
\hline
\end{tabular}

Table 3. Values of the dynamic parameters of the human physical model specified in the ISO 10068 standard (ISO 10068:1998)

\begin{tabular}{|c|c|c|c|c|}
\hline \multirow{2}{*}{ Parameter } & \multirow{2}{*}{ Unit } & \multicolumn{4}{|c|}{ The direction of hand-arm vibration } \\
\cline { 3 - 5 } & & $x$ & $y$ & $z$ \\
\hline \hline$m_{1}$ & $\mathrm{~kg}$ & 3.0952 & 3.2462 & $\mathbf{2 . 9 0 2 3}$ \\
\hline$m_{2}$ & $\mathrm{~kg}$ & 0.486 & 0.3565 & $\mathbf{0 . 6 6 2 3}$ \\
\hline$m_{3}$ & $\mathrm{~kg}$ & 0.0267 & 0.0086 & $\mathbf{0 . 0 2 9 9}$ \\
\hline$k_{1}$ & $\mathrm{~N} / \mathrm{m}$ & 1565 & 6415 & $\mathbf{2 4 9 5}$ \\
\hline$k_{2}$ & $\mathrm{~N} / \mathrm{m}$ & 132 & 300 & $\mathbf{2 9 9 4 0 0}$ \\
\hline$k_{3}$ & $\mathrm{~N} / \mathrm{m}$ & 4368 & 27090 & $\mathbf{5 3 3 5}$ \\
\hline$c_{1}$ & $\mathrm{~N} \cdot \mathrm{s} / \mathrm{m}$ & 9.10 & 30.78 & $\mathbf{3 0 . 3 0}$ \\
\hline$c_{2}$ & $\mathrm{~N} \cdot \mathrm{s} / \mathrm{m}$ & 18.93 & 51.75 & $\mathbf{3 8 0 . 6}$ \\
\hline$c_{3}$ & $\mathrm{~N} \cdot \mathrm{s} / \mathrm{m}$ & 207.5 & 68 & $\mathbf{2 2 7 . 5}$ \\
\hline
\end{tabular}

for the ISO 10068-based model with three-point reduction. The percentage increase between the models is given by the formula

$$
I_{P}=\frac{P_{\mathrm{DONG}(\mathrm{RMS}), f}}{P_{\mathrm{ISO}(\mathrm{RMS}), f}} \cdot 100 \%
$$

where $P_{\mathrm{DONG}(\mathrm{RMS}), f}$ is the effective value of the power of inertia, loss or elasticity in the entire Human-Tool system obtained under the new model at specific frequency - power (RMS) in [W]: — power of inertia expressed in [W]

$$
\begin{aligned}
& P_{\text {DONG INe }, f}=\sqrt{\frac{1}{t} \int_{0}^{t}\left[m_{1} \ddot{z}_{1} \dot{z}_{1}\right]^{2} d t}+\sqrt{\frac{1}{t} \int_{0}^{t}\left[m_{2} \ddot{z}_{2} \dot{z}_{2}\right]^{2} d t}+\sqrt{\frac{1}{t} \int_{0}^{t}\left[m_{3} \ddot{z}_{3} \dot{z}_{3}\right]^{2} d t} \\
& +\sqrt{\frac{1}{t} \int_{0}^{t}\left[\left(m_{4}+m_{5}+m_{N}\right) \ddot{z}_{4} \dot{z}_{4}\right]^{2} d t}
\end{aligned}
$$


— power of loss expressed in [W]

$$
\begin{gathered}
P_{\text {DONG LOS }, f}=\sqrt{\frac{1}{t} \int_{0}^{t}\left[\left(c_{1}+c_{2}\right) \dot{z}_{1}^{2}\right]^{2} d t}+\sqrt{\frac{1}{t} \int_{0}^{t}\left[\left(c_{2}+c_{3}+c_{4}\right) \dot{z}_{2}^{2}\right]^{2} d t} \\
+\sqrt{\frac{1}{t} \int_{0}^{t}\left[\left(c_{3}+c_{5}\right) \dot{z}_{3}^{2}\right]^{2} d t}+\sqrt{\frac{1}{t} \int_{0}^{t}\left[\left(c_{4}+c_{5}\right) \dot{z}_{4}^{2}\right]^{2} d t}
\end{gathered}
$$

— power of elasticity expressed in [W]

$$
\begin{gathered}
P_{\text {DONG ELA }, f}=\sqrt{\frac{1}{t} \int_{0}^{t}\left[\left(k_{1}+k_{2}\right) z_{1} \dot{z}_{1}\right]^{2} d t}+\sqrt{\frac{1}{t} \int_{0}^{t}\left[\left(k_{2}+k_{3}+k_{4}\right) z_{2} \dot{z}_{2}\right]^{2} d t} \\
+\sqrt{\frac{1}{t} \int_{0}^{t}\left[\left(k_{3}+k_{5}\right) z_{3} \dot{z}_{3}\right]^{2} d t}+\sqrt{\frac{1}{t} \int_{0}^{t}\left[\left(k_{4}+k_{5}\right) z_{4} \dot{z}_{4}\right]^{2} d t}
\end{gathered}
$$

$P_{\mathrm{ISO}(\mathrm{RMS}), f}$ is the effective value of the power of inertia, loss or elasticity in the entire Human-Tool system obtained under the ISO 10068-based model at specific frequency-power (RMS) in $[\mathrm{W}]$ :

- power of inertia expressed in $[\mathrm{W}]$

$$
P_{\mathrm{ISO} \text { INE }, f}=\sqrt{\frac{1}{t} \int_{0}^{t}\left[m_{1} \ddot{z}_{1} \dot{z}_{1}\right]^{2} d t}+\sqrt{\frac{1}{t} \int_{0}^{t}\left[m_{2} \ddot{z}_{2} \dot{z}_{2}\right]^{2} d t}+\sqrt{\frac{1}{t} \int_{0}^{t}\left[\left(m_{3}+m_{N}\right) \ddot{z}_{3} \dot{z}_{3}\right]^{2} d t}
$$

- power of loss expressed in $[\mathrm{W}]$

$$
P_{\mathrm{ISO} \mathrm{LOS}, f}=\sqrt{\frac{1}{t} \int_{0}^{t}\left[\left(c_{1}+c_{2}\right) \dot{z}_{1}^{2}\right]^{2} d t}+\sqrt{\frac{1}{t} \int_{0}^{t}\left[\left(c_{2}+c_{3}\right) \dot{z}_{2}^{2}\right]^{2} d t}+\sqrt{\frac{1}{t} \int_{0}^{t}\left[c_{3} \dot{z}_{3}^{2}\right]^{2} d t}
$$

- power of elasticity expressed in $[\mathrm{W}]$

$$
P_{\mathrm{ISO} \text { eLA }, f}=\sqrt{\frac{1}{t} \int_{0}^{t}\left[\left(k_{1}+k_{2}\right) z_{1} \dot{z}_{1}\right]^{2} d t}+\sqrt{\frac{1}{t} \int_{0}^{t}\left[\left(k_{2}+k_{3}\right) z_{2} \dot{z}_{2}\right]^{2} d t}+\sqrt{\frac{1}{t} \int_{0}^{t}\left[k_{3} z_{3} \dot{z}_{3}\right]^{2} d t}
$$

The results presented in Fig. 3 indicate that the new model (Dong et al., 2007) with four degrees of freedom is not comparable to the model specified in the ISO 10068 standard. The biggest increments in the power of elasticity can be observed in variant I and IV, where, depending on the frequency, the inconsistency between the models ranges from $66 \%$ up to as much as $519 \%$. In variant III, the difference between the models decreases, ranging from $34 \%$ to $373 \%$. The highest degree of correspondence is exhibited in variant II, where the increase in the power of elasticity ranges from $1 \%$ to $222 \%$.

The situation is much better in the case of the contribution of other types of power. The difference between the models in terms of the power of dissipation ranges from $12 \%$ to $132 \%$, whereas in the case of the power of inertia - from $0.03 \%$ to $20 \%$. Assuming the relative error of $30 \%$ between the models, it can be assumed that the results obtained for variant II are correct, but only at an operational frequency of $16 \mathrm{~Hz}$ and $90 \mathrm{~Hz}$. Under more stringent compatibility 
(a)

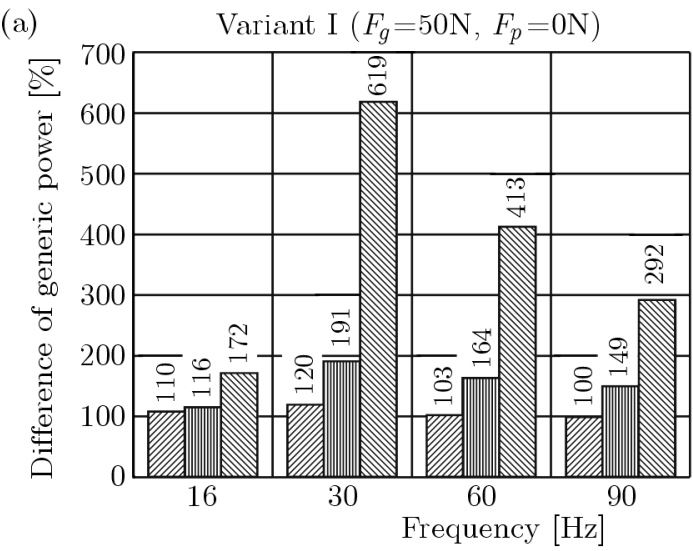

(c)

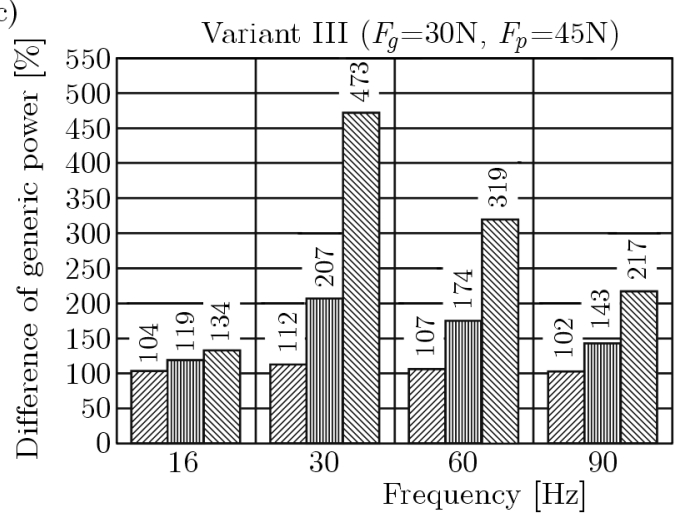

(b)

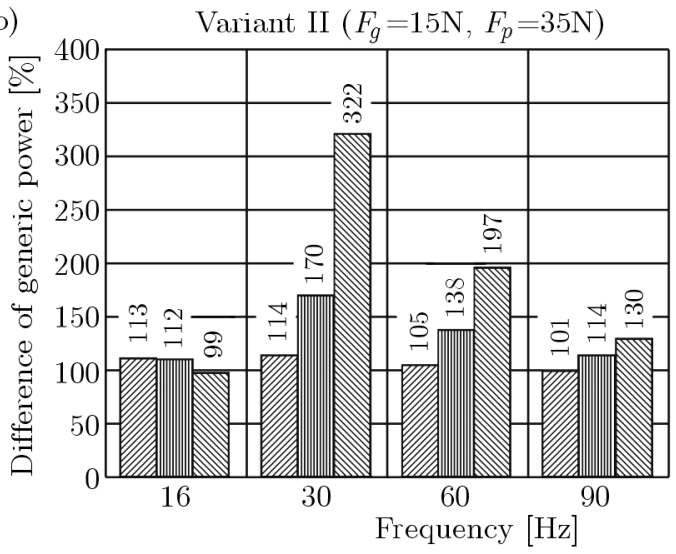

(d)

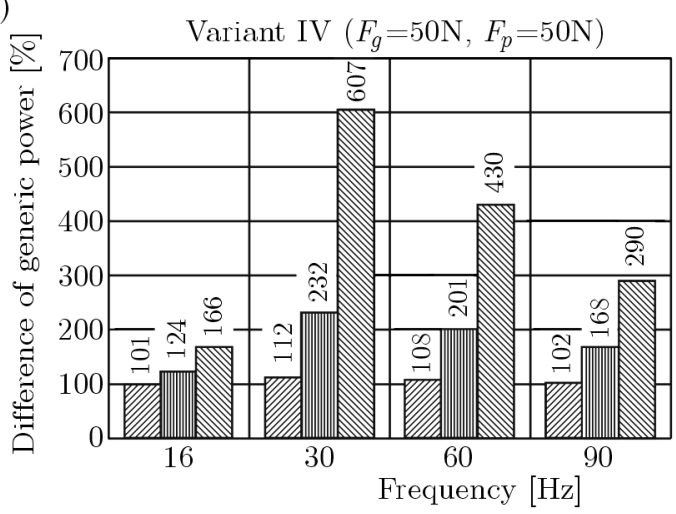

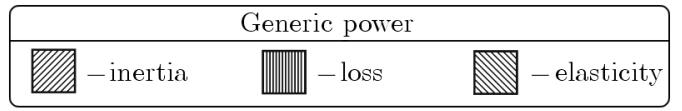

Fig. 3. The influence of frequency $f$ on the percentage increase in three types of power for the new model for different values of the grip force $F_{g}$ and push force $F_{p}$ in relation to the model specified in ISO 10068: (a) variant I, (b) variant II, (c) variant III, (d) variant IV

criteria (the relative error of, say, 10\%) none of the conditional variants of the tested model could be used at the operational frequencies of the Human-Tool system.

Figure 4 shows the influence of the frequency of driving impulses $f$ on the percentage increase in total power, which is the sum of the three types of power in the new model relative to the values obtained for the reference model specified in the ISO 10068 standard (ISO 10068:1998). The above relationship can be expressed by the formula

$$
I_{G}=\frac{P_{\mathrm{DONG} \mathrm{INE}, f}+P_{\mathrm{DONG} \mathrm{LOS}, f}+P_{\mathrm{DONG} \mathrm{ELA}, f}}{P_{\mathrm{ISO} \text { INE }, f}+P_{\mathrm{ISO} \mathrm{LOS}, f}+P_{\mathrm{ISO} \mathrm{ELA}, f}} \cdot 100 \%
$$

The comparison reveals that the highest degree of compliance between the new model and the model specified in the ISO 10068 standard, regardless of the frequency $f$, can be observed for variant II.

In addition, for each conditional variant, the largest difference could be observed at the frequency $f=30 \mathrm{~Hz}$. The cause of such increments is the frequency $f$, which is similar to resonant frequencies of the subsystems (Table 4). The greatest degree of similarity (the smallest difference) has been recorded for the highest frequency $(f=90 \mathrm{~Hz})$, where the increase between the models ranged from $4 \%$ to $21 \%$.

Assuming the relative error of $25 \%$, it can be concluded that for each conditional variant the values obtained with the new model (Dong et al., 2007) are true, but only at the frequency $f=90 \mathrm{~Hz}$. It is worth noting that the second conditional variant can also be used for research 

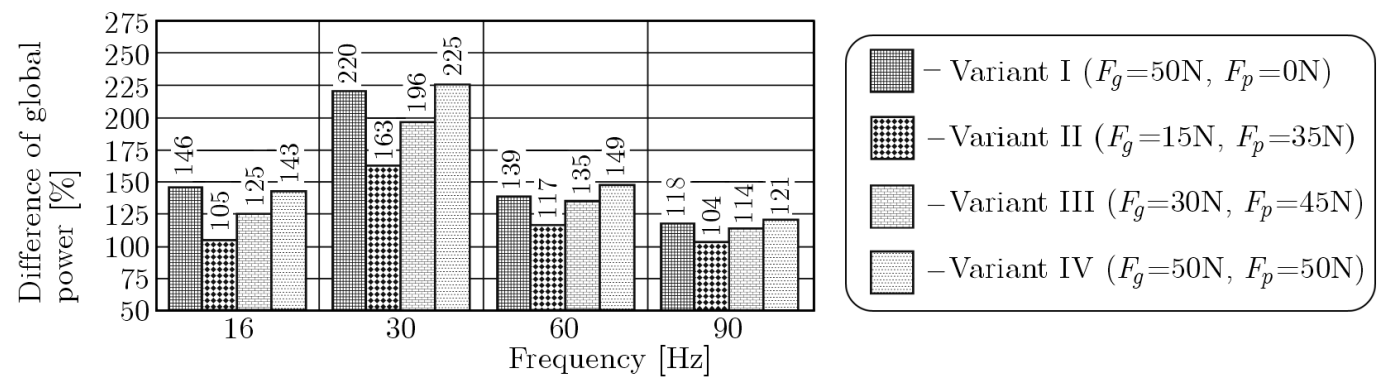

Fig. 4. The influence of frequency $f$ on the percentage increase in total power for the new model in relation to the model specified in ISO 10068 (ISO 10068:1998)

purposes, assuming the same level of the relative error. The results for this variant are similar to those specified in the standard, but not in all operational frequencies of the system Human-Tool (the highest discrepancy at the frequency $30 \mathrm{~Hz}$ ).

Table 4. Resonant frequencies of the human models at each point of reduction

\begin{tabular}{|c|c|c|c|c|c|c|c|}
\hline \multicolumn{7}{|c|}{ Model used } \\
\cline { 1 - 5 } The new (tested) model & \multicolumn{3}{|c|}{ ISO 10068 model } \\
\hline Variant & $j=1$ & $j=2$ & $j=3$ & $j=4$ & $j=1$ & $j=2$ & $j=3$ \\
\hline \multicolumn{7}{|c|}{ Resonant frequency of subsystem [Hz] } \\
\hline \hline I & 8.37 & 26.04 & 223.7 & 27.73 & & & \\
\cline { 1 - 5 } II & 9.04 & 36.44 & 134.1 & 19.94 & \multirow{2}{*}{51.33} & 107.96 & \multirow{2}{*}{4.73} \\
\hline III & 8.79 & 37.41 & 178.2 & 24.67 & & & \\
\hline IV & 8.96 & 34.38 & 212.5 & 28.70 & & & \\
\hline
\end{tabular}

Figure 5 presents a comparison of the percentage share of the energy input at individual points of reduction on the basis of the amount of power which is the sum of three types of power, at different frequencies $f$. It can be expressed in the following equation

$$
L=\frac{P_{\mathrm{INE}(\mathrm{RMS}), j}+P_{\mathrm{LOS}(\mathrm{RMS}), j}+P_{\mathrm{ELA}(\mathrm{RMS}), j}}{\sum_{j=1}^{s} P_{\mathrm{INE}(\mathrm{RMS}), j}+\sum_{j=1}^{s} P_{\mathrm{LOS}(\mathrm{RMS}), j}+\sum_{j=1}^{s} P_{\mathrm{ELA}(\mathrm{RMS}), j}} \cdot 100 \%
$$

where $P_{\mathrm{INE}(\mathrm{RMS}), j}, P_{\mathrm{LOS}(\mathrm{RMS}), j}$ and $P_{\mathrm{ELA}(\mathrm{RMS}), j}-$ power of inertia, loss and elasticity, respectively, at the point of reduction obtained with a particular model and its conditional variant at a specific frequency-power (RMS) in [W].

In order to compare the energy inputs at various points of reduction in both models, a theoretical value has been introduced, which is equal to the sum of powers at the points of reduction corresponding to the same part of the operator's hand in the model. The values of power at the third point of reduction $\left(z_{3}\right)$ have been added to these obtained at the fourth point of reduction $\left(z_{4}\right)$ with the new model (Dong et al., 2007). The resulting sum of power at the theoretical point has been compared with a corresponding value obtained with the model specified in the ISO 10068 standard (ISO 10068:1998).

The results shown in Fig. 5 indicate that the four sets of dynamic parameters corresponding to different conditional variants of the hand interacting with the handle of the tool proposed by the authors in Dong et al. (2007) do not affect the order of energy inputs at the points of reduction, but they do have an impact on energy input values at individual points of reduction. Based on the percentage share of the energy input at individual points of reduction, it is possible to establish the order of energy input exerted on the biological structure in the new human physical model in terms of the sum of the three kinds of power.

The order of energy inputs in the new physical human model is independent of the frequency $f$ and is as follows: first, the theoretical point $\left(z_{3}+z_{4}\right)-67 \%-99 \%$, second, Palm-Wrist-Forearm $\left(z_{2}\right)$ 
(a)

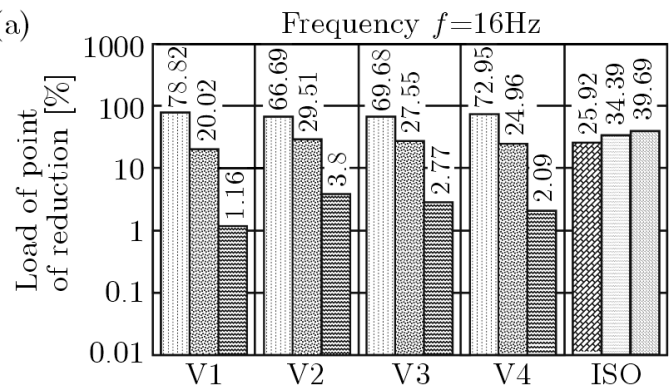

(c)

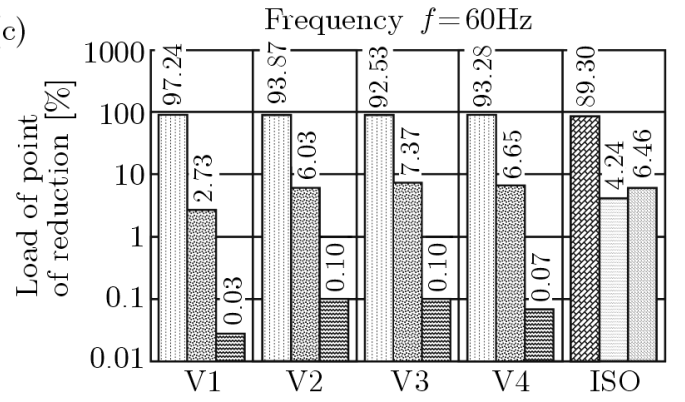

(b)

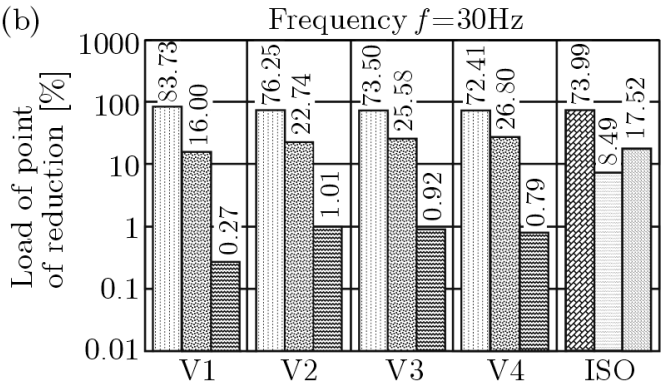

(d)

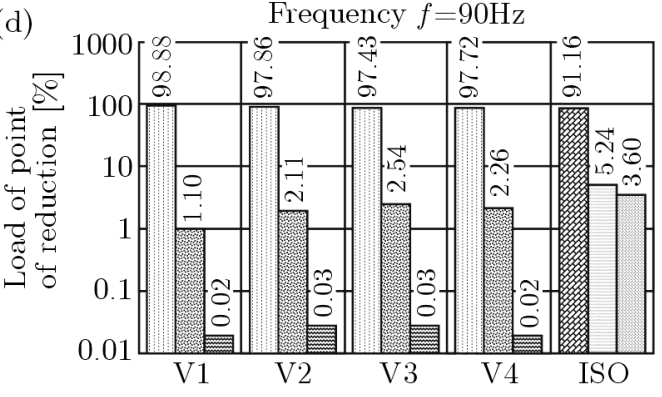

\begin{tabular}{|c|c|c|c|}
\hline \multicolumn{4}{|c|}{ Point of reduction } \\
\hline Dong: & -theoretical point $\left(z_{3}+z_{4}\right)$ & - Palm-Wirst-Forearm $\left(z_{2}\right)$ & -Upper Arm-Shoulder $\left(z_{1}\right)$ \\
\hline ISO: & 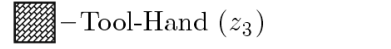 & - Forearm-Elbow $\left(z_{2}\right)$ & $\square$ - Arm-Shoulder $\left(z_{1}\right)$ \\
\hline
\end{tabular}

Fig. 5. The percentage change of the energy input at points of reduction in terms of the sum of three types of power for both models and their conditional variants at different frequencies: (a) $f=16 \mathrm{~Hz}$,

(b) $f=30 \mathrm{~Hz},(\mathrm{c}) f=60 \mathrm{~Hz},(\mathrm{~d}) f=90 \mathrm{~Hz}$

- 1\%-30\% and third, Upper Arm-Shoulder $\left(z_{1}\right)-0.02 \%-4 \%$. In the model specified in the ISO 10068:1998 standard, the order of energy inputs at individual points of reduction depends on the frequency $f$. At $f=16 \mathrm{~Hz}$ the highest energy input is recorded at the reduction point of Shoulder-Arm $\left(z_{1}\right)-40 \%$, this is followed by Forearm-Elbow $\left(z_{2}\right)-34 \%$ and finally ToolHand $\left(z_{3}\right)-26 \%$. At higher frequencies the highest energy input is observed at the reduction point of Tool-Hand, which is, just like in the case of the new physical human model, the point nearest the tool. What is different, however, is the order of points - Fig. 5b and 5c. The same order of energy input values at individual points of reduction with the tested model has been observed only at $f=90 \mathrm{~Hz}$. At this frequency, the energy input at the points of reduction decreased the more points have been removed from the tool, in the following manner: $91 \%$ at the point Tool-Hand $\left(z_{3}\right)$, over $5 \%$ at Forearm-Elbow $\left(z_{2}\right)$ and less than $4 \%$ at Arm-Shoulder $\left(z_{1}\right)$.

\section{Conclusions}

The comparison of energy inputs revealed that the models in questions are not comparable to each other in terms of the power of elasticity and loss, since the levels of these powers in the models differ. The energy analysis shows a higher degree of similarity between the models in terms of the percentage share of total power in comparison with their individual components, that is the three types of power. Based on the results of power distribution, it is possible to formulate four conditional variants of the new human physical model in terms of their similarity to the reference system, i.e. the model specified in ISO 10068:1998 (Table 5).

Developing the new model in further research and assuming the relative error of $25 \%$, it can be assumed that the values obtained for each conditional variant are correct, but only at the frequency $f=90 \mathrm{~Hz}$. It is worth noting that the second conditional variant can also be used 
Table 5. The relative error between the models (in terms of total power - Fig. 4)

\begin{tabular}{|l|c|c|c|c|}
\hline \multirow{2}{*}{$\begin{array}{c}\text { New (tested) } \\
\text { model }\end{array}$} & \multicolumn{4}{|c|}{ Frequency } \\
\cline { 2 - 5 } & $16 \mathrm{~Hz}$ & $30 \mathrm{~Hz}$ & $60 \mathrm{~Hz}$ & $90 \mathrm{~Hz}$ \\
\hline \hline Variant II & $2 \%$ & $47 \%$ & $14 \%$ & $2 \%$ \\
\hline Variant III & $22 \%$ & $78 \%$ & $31 \%$ & $12 \%$ \\
\hline Variant I & $43 \%$ & $101 \%$ & $36 \%$ & $16 \%$ \\
\hline Variant IV & $40 \%$ & $104 \%$ & $45 \%$ & $20 \%$ \\
\hline
\end{tabular}

for research purposes, keeping in mind its high level of discrepancy at the frequency $30 \mathrm{~Hz}$ in comparison with the model specified in ISO 10068:1998.

The topic requires further research. The analysis presented in the study can be extended to include other characteristics of driving impulses, for example the real impulse of pulsed forces occurring during work with hitting impact tools. Further studies should also be conducted for a wider range of frequency $f$ in order to examine the similarity of the models at higher frequencies, i.e. above $90 \mathrm{~Hz}$.

In order to confirm the adequacy of the models, they should be verified by energy measurements in a laboratory. Such verification could be performed at the Laboratory of Dynamics and Ergonomics of the Human-Technical Object-Environment Metasystem at Poznan University of Technology. The research in this area will be continued.

\section{References}

1. Adewusi S., Rakheja S., Marcotte P., 2012, Biomechanical models of the human handarm to simulate distributed biodynamic responses for different postures, International Journal of Industrial Ergonomics, 42, 2, 249-260

2. Dobry M.W., 1998, Optimization of the Energy Flow in the Human-Tool-Base System (in Polish), Rozprawa habilitacyjna, Seria "Rozprawy" nr 330, ISSN 0551-6528, Wyd. Politechniki Poznańskiej, Poznań

3. Dobry M.W., 2001, Energy diagnostics and assessment of dynamics of mechanical and biomechatronics systems, Machine Dynamics Problems, 25, 35-54

4. Dobry M.W., 2004, Energy Diagnosis of Technical Systems (in Polish), Inżynieria Diagnostyki Maszyn, Polskie Towarzystwo Diagnostyki Technicznej, Instytut Technologii Eksploatacji, Warszawa, Bydgoszcz, Radom, 314-339

5. Dobry M.W., 2012, Fundamentals of Energy Diagnostics of Mechanical and Biomechanical Systems (in Polish), Wydawnictwo Naukowe Instytutu Technologii Eksploatacji - PIB, Poznań-Radom

6. Dong J.H., Dong R.G., Rakheja S., Wu J., 2007, Predictions of the distributed biodynamic responses in the hand-arm system, 11th International Conference on Hand-Arm Vibration, Bologna, Italy

7. Griffin M.J., 1990, Handbook of Human Vibration, Academic Press, London

8. Meltzer G., 1981, A vibration model for the human hand-arm-system, Studies in Environmental Science, 13, 210-221

9. Reynolds D.D., Soedel W., 1972, Dynamic response of the hand-arm system to a sinusoidal input, Journal of Sound and Vibration, 21, 3, 339-353

10. ISO 10068:1998, Mechanical vibration and shock - Free, mechanical impedance of the human handarm system at the driving point 